\title{
Correspondence
}

Editor: Ian Pullen

Contents: Multiple personality disorder/Preconscious perceptual processing/Reconquest of the subjective/Guilt or morbid remorse?/Availability of the Hospital Anxiety and Depression (HAD) scale/ Fingerprints and statistics/Hemispheric imbalance in schizophrenia/Applicability of psychotherapy for non-Western people/Psychological outcome of abortion/'Socrates' symptom'/Clozapine in the community/ECT anaesthetics/Out-patient ECT for depression in a man with moderate learning disability/Are polioviruses a cause of schizophrenia?/ Supervision of repeat antidepressant prescribing in general practice.

\section{Multiple personality disorder}

SIR: We read with interest the article by Merskey (Journal, March 1992, 160, 327-340), in which he examined a number of cases of multiple personality disorder (MPD) from the earlier literature, in order to determine whether there is any evidence that MPD was ever a spontaneous phenomenon.

Since human behaviour can be understood if we have sufficient information about a person's development-his biological, psychological and sociological history - (Ewalt et al, 1957) we would direct attention towards inheritance of ancestral beliefs in the aetiology of psychopathology. In particular, we would underline the concept of soul in an anthropological context.

Frazer (1922) reports a number of races in whom there was a belief that several souls were harboured in the same body. For example, he reports that the Caribbeans believed that there is a soul in the head, another in the heart, and others in all the points in which there is an arterial pulse. The indian Hidatsa interpreted the phenomenon of agony, supposing that man has four souls, which leave the body in succession. The Daiachi of Borneo and the Malesian believed that every man has seven souls and the Alfur of Minahassa (Celebes) believed that there are three souls. The indians of Laos supposed that the body is the seat of 30 souls.

Evidently, these primitive beliefs, and subsequently the religious beliefs, show evocative similarities with MPD, and suggest the presence of univocal elements of thought with different types of behaviour, with respect to different times and places.

We conclude with two remarks. First, since the developmental history of our species casts an unmistakable shadow on our mental lives, the comprehension of psychopathological behaviour may be facilitated by an ethnological approach. Second, in a multicultural Europe, the transcultural approach to clinical problems is more and more necessary (Cox, 1991).

Cox, J. L. (1991) Transcultural psychiatry. British Journal of Psychiatry, 158, 579-582.

Ewalt, J. J. B., Strecker, E. A. \& Ebaugh, F. G. (eds) (1957) The development of a normal personality. In Practical Clinical Psychiatry (8th edn) p. 3. New York: McGraw Hill.

Frazer, J. G. (1922) The Golden Bough. A Study in Magic and Religion, pp. 799-801. London: Macmillan.

\section{Paolo Novello}

Department of Neurology

Alberto Prima vera

\section{University of Genoa}

Italy

SIR: The recent questions and concerns raised in the Journal about the "unprecedented numbers" of cases of multiple personality disorder (MPD) diagnosed in North America require a response (Merskey, Journal, March 1992, 160, 327-340). Although the diagnosis of MPD has received attention and support in Europe and Latin America, there is a strong resistance in Britain to accepting this condition. There it is argued: (a) that MPD is a misdiagnosis of organic conditions or bipolar illness; or (b) created by iatrogenic suggestion; or (c) induced in suggestible patients by popularised accounts in the media.

The arguments against the validity of MPD made thus far in the Journal rely on examination of historical or dramatised accounts of the condition and inexplicably fail to examine the large number of modern scientific studies published in reputable journals. These increasingly sophisticated studies, using standardised measures and structured diagnostic interviews available to all interested professionals, have documented the existence of a complex psychiatric syndrome that is frequently misdiagnosed. The 